\title{
Strengthening and Toughening of Titanium Alloys
}

\author{
Yoshikuni KAWABE and Seiichi MUNEKI
}

Tsukuba Laboratories, National Research Institute for Metals, Sengen, Tsukuba, Ibaraki-ken, 305 Japan.

(Received on January 7, 1991; accepted in final form on January 25, 1991)

\begin{abstract}
This paper will summarize the strengthening and toughening behaviors of $\alpha+\beta$ and $\beta$ alloys at room temperature. In addition, some considerations on the strengthening capacity and some relationships between microstructures and mechanical properties will be presented.

The strength of $\alpha+\beta$ alloys can be improved by increasing the volume fraction of the $\beta$ phase and using an ultra refinement of an equiaxed $\alpha$ structure. On the other hand, the toughness can be improved by adjusting an acicular $\alpha$ structure. The strength of $\beta$ alloys can be increased by the homogeneous and fine precipitation of the $\alpha$ phase and by the $\beta$ grain refinement. The toughness of $\beta$ alloys is usually superior to that of $\alpha+\beta$ alloys at given strength levels. This is mainly due to the disappearance of the coarse primary $\alpha$ phase in $\beta$ alloys.

Increases in the strength of smooth, notched and precracked specimens are limited by ductility, notched tensile strength and fracture toughness, respectively. As a result, there is a critical value for strengthening for each specimen. Finally, some guidelines for microstructural modification for optimization of the strength-ductility and strength-toughness balance will be presented.
\end{abstract}

KEY WORDS: titanium alloys; strengthening; toughening; strength-ductility balance; strength-toughness balance; microstructure-property relationships.

\section{Introduction}

The strengthening and toughening of materials are the most important research subjects for structural materials. However, the strength and toughness of high strength metallic materials are characteristics which are opposed to each other and toughness generally reduces with an increase in strength level. Therefore, strengthening of alloys has been performed from the point of view of improving the strength-toughness balance to as high level as possible.

In the field of titanium alloys, a Ti-6Al-4V $\alpha+\beta$ alloy has been primarily used for a large number of applications. Recently, there has been a strong demand for the development of alloys having a higher strength together with excellent formability, and new $\beta$ alloys have been developed. ${ }^{1)}$ Research for the strengthening of $\beta$ alloys has been actively performed in Japan, although development has not yet progressed as far.

This paper will explain the trends in research on the strengthening and toughening of titanium alloys based on the results of the recent advances in Japan. In addition, some considerations on the strengthening capacity and some examples of the relationship between microstructures and mechanical properties will be presented.

\section{Trends of Strengthening}

Titanium alloys can be divided into three groups of $\alpha$, $\alpha+\beta$ and $\beta$ alloys according to their microstructures at room temperature. Of these, this section will explain the strengthening behaviors of $\alpha+\beta$ and $\beta$ alloys.

\section{1. $\alpha+\beta$ Alloy}

A representative $\alpha+\beta$ alloy is the $\mathrm{Ti}-6 \mathrm{Al}-4 \mathrm{~V}$ alloy. Since this alloy consists of $\alpha$ and $\beta$ phases, its strength characteristics can be varied over a considerable range through control of the volume fraction and morphology of both phases. For example, the tensile strength of this alloy is about $900 \mathrm{MPa}$ in an annealed condition and about $1200 \mathrm{MPa}$ in a solution treated and aged condition. An increase in strength of about $300 \mathrm{MPa}$ can be achieved using the solution and aging treatments.

This is due to the microstructural refinement and phase transformation in the prior $\beta$ phase region as follows:

(1) Homogeneous and fine dispersion of the primary $\alpha$ phase can be enhanced by subjecting the alloy to the solution treatment after hot working in the $(\alpha+\beta)$ phase region.

(2) Fine precipitation of the secondary $\alpha$ phase occurs in the prior $\beta$ phase region during the subsequent aging treatment.

Accordingly, increasing the volume fraction of the $\beta$ phase, namely by the design of a $\beta$-rich $\alpha+\beta$ alloy system, is very effective in increasing the strength of the alloy. It has been reported $^{2)}$ that a tensile strength of about $1400 \mathrm{MPa}$ can be achieved in a $\beta$-rich $\alpha+\beta$ alloy which has a composition of $\mathrm{Ti}-4.5 \mathrm{Al}-3 \mathrm{~V}-2 \mathrm{Fe}-2 \mathrm{Mo}$.

Another method for strengthening is to use an ultra refinement of an equiaxed $\alpha$ structure. Although such 
Table 1. Chemical composition and tensile properties of main $\beta$ titanium alloys.

\begin{tabular}{|c|c|c|c|c|c|c|c|c|c|}
\hline \multirow{2}{*}{ Alloys } & \multicolumn{7}{|c|}{ Chemical composition (wt \%) } & \multicolumn{2}{|c|}{ Tensile properties* } \\
\hline & Mo & $\mathrm{V}$ & $\mathrm{Cr}$ & $\mathrm{Fe}$ & Al & $\mathrm{Sn}$ & $\mathrm{Zr}$ & $\begin{array}{l}\text { Tensile strength } \\
\text { (MPa) }\end{array}$ & $\begin{array}{c}\text { Elongation } \\
(\%)\end{array}$ \\
\hline $13-11-3$ & - & 13 & 11 & - & 3 & - & - & 1280 & 8 \\
\hline Beta III & $\mathrm{I} 1.5$ & - & - & - & - & 4.5 & 6 & 1380 & 11 \\
\hline $10-2-3$ & - & 10 & - & 2 & 3 & - & - & 1220 & 8 \\
\hline $\mathrm{Ti}-17$ & 4 & - & 4 & - & 5 & 2 & 2 & 1220 & 12 \\
\hline $15-3-3-3$ & - & 15 & 3 & - & 3 & 3 & - & 1220 & 10 \\
\hline Beta C & 4 & 8 & 6 & - & 3 & - & 4 & 1440 & 7 \\
\hline $15-5-3$ & 15 & - & - & - & 3 & - & 5 & 1470 & 14 \\
\hline
\end{tabular}

* Properties under an appropriate heat treatment.

microstructural features can usually be controlled by hot working in the $(\alpha+\beta)$ phase region, there is a limit to the degree of refinement which can be achieved using hot working alone. It is reported ${ }^{3)}$ that an ultra refined microstructure of about $1 \mu \mathrm{m}$ in diameter can be obtained through a microstructural modification of a $\mathrm{Ti}-6 \mathrm{Al}-4 \mathrm{~V}$ alloy using temporary alloying with hydrogen. This treatment consists of hydrogenation, controlling the dislocation structure by working and heat treatment and dehydrogenation. Ultra refinement can be achieved in the step of dehydrogenation because it is accompanied by recrystallization. This is expected to increase both the strength and ductility.

\section{2. $\beta$ Alloy}

The $\beta$ alloy is an alloy in which the $\beta$ phase can be retained at room temperature. All commercial $\beta$ alloys are metastable alloys with secondary phase precipitation during subsequent aging. Hence, strengthening in $\beta$ alloys is mainly caused by the precipitation hardening mechanism and has characteristics as follow;

(1) Excellent formability and high strength which are opposed to each other can be provided in different stages of the manufacturing process.

(2) Attainable strength is higher than that of $\alpha+\beta$ alloys.

(3) Toughness obtained is superior to that of $\alpha+\beta$ alloys at given strength levels.

(4) Severe embrittlement occurs in some instances according to the kind or morphology of precipitates.

Note that $\beta$ alloys greatly increase the strengthening capacity for titanium alloys.

Table 1 shows the chemical composition and tensile properties under an appropriately heat treated condition. $\beta$ alloys belong to a highly alloyed system and contain a large amount of $\beta$ stabilizing elements as well as $\alpha$ stabilizing elements and neutral elements. These alloy systems have been selected to adjust the $\beta$ phase stability and to control precipitation behaviors. Figure 1 shows a schematic TTT diagram. ${ }^{4)}$ Metastable $\omega$ phases precipitate at lower aging temperatures and stable $\alpha$ phases precipitate at higher temperatures. The transition reaction from $\omega$ to $\alpha$ phase occurs at intermediate temperatures. As the $\omega$ phase homogeneously and finely precipitates in the microstructure, it leads to a large increase in hardness, but is usually accompanied by severe

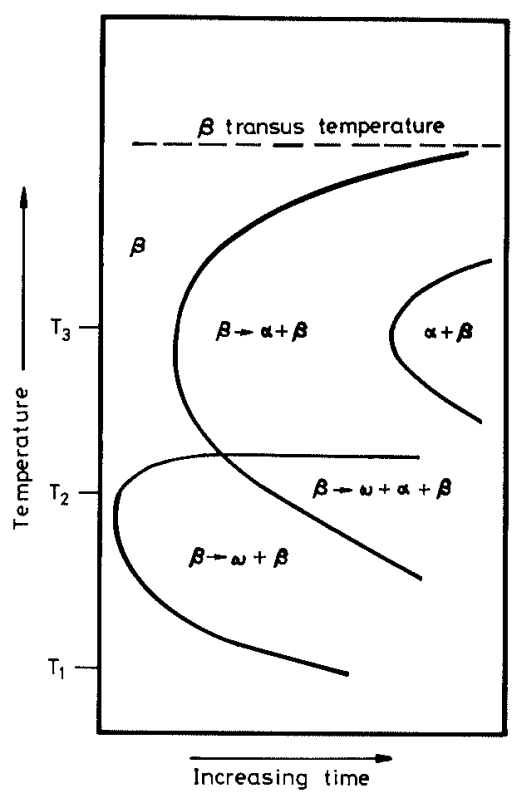

Fig. 1. Schematic TTT diagram for representative $\beta$ alloy.

embrittlement. Therefore, precipitation hardening using the $\omega$ phase can not be utilized as a strengthening treatment.

The yield strength of $\beta$ alloys after aging can be expressed by the following empirical formula. ${ }^{5}$ )

$$
\sigma_{0.2}=850+70 d^{-1}
$$

where, $\sigma_{0.2}: 0.2 \%$ yield strength $(\mathrm{MPa})$

$$
d \text { : interparticle spacing of } \alpha \text { phase }(\mu \mathrm{m}) \text {. }
$$

It is essential for the strengthening of $\beta$ alloys that the $\alpha$ phase precipitates homogeneously and finely. Microstructure modifications as follows have been attempted.

(1) As there is a tendency for the $\alpha$ phase to precipitate preferentially at grain boundaries when the $\beta$ phase stability is too high, the stability is properly adjusted to the characteristics required.

(2) Preferential precipitation of the $\alpha$ phase at grain boundaries is retarded by grain refinement.

(3) Homogeneous precipitation of the $\alpha$ phase in the grain is enhanced by control of the dislocation structure.

(4) The growth rate of the $\alpha$ phase is retarded by selecting as low an aging temperature as possible.

(5) Homogeneous precipitation of the $\alpha$ phase is 
enhanced by using the double aging treatment.

Among these, controlling the dislocation structure is most effective for obtaining the homogeneous and fine precipitation of the $\alpha$ phase. Effective methods can be divided into the following three groups.

a) Cold working,

b) Cold working and recovery treatment, and

c) Warm working.

In particular, it has been reported $^{6)}$ that the strength-ductility balance can be improved more by warm working than by cold working.

As far as the morphology of the $\alpha$ phase is concerned, another factor affecting mechanical properties is the size of the $\alpha$ phase. Below a critical size, the $\alpha$ phase tends to be coherent with the matrix and takes the form of deformable precipitates; in other words, shearing type deformation occurs across the precipitates. This leads to a decrease in strength. In addition, this mode of deformation concentrates the strain on a particular slip plane and exhibits an embrittlement effect. The critical size of the $\alpha$ phase also depends on its hardness. Hence, an addition of $\mathrm{Al}$ to $\beta$ alloys is necessary to harden the $\alpha$ precipitates. It is also undesirable to select an aging treatment at too low temperatures, even in the $\alpha$ precipitated region.

Figure $2^{7)}$ shows a collection of ductility (reduction in area) values as a function of tensile strength for various $\beta$ alloys. These data were obtained under a wide variety of solution treated and aged conditions and are the results for samples subjected to the heat treatment as the sole mean of microstructure modification. Although there is a tendency for the ductility to be reduced with an increase in the strength level, the ductility values can be divided into two groups. The group with higher ductility consists of the results for samples strengthened using an appropriate size of $\alpha$ precipitates together with the fine $\beta$ grained structure. On the other hand, the group with lower ductility consists of the results for samples which

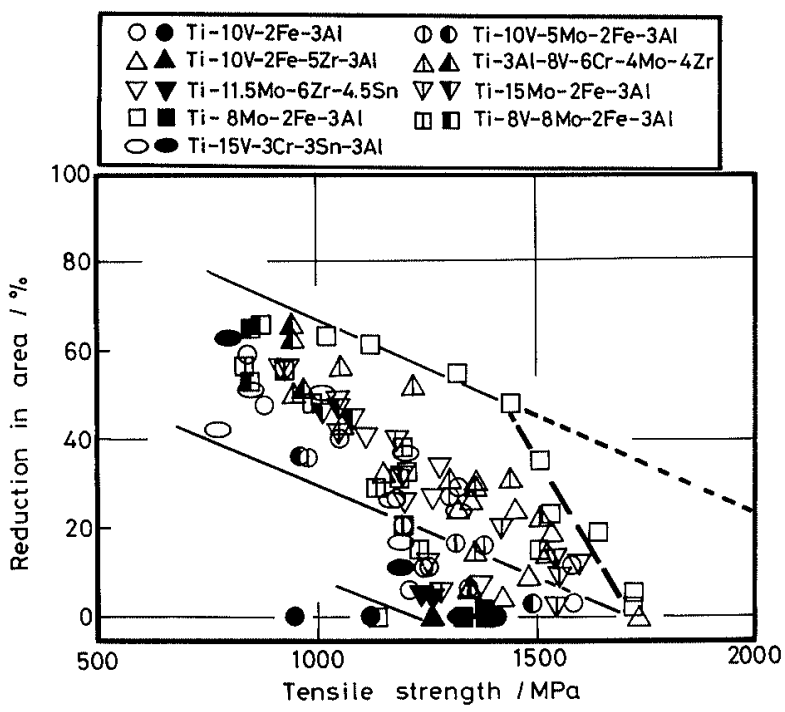

Fig. 2. Relationship between ductility (reduction in area) and yield strength for various $\beta$ alloys.

Open circles indicate samples aged at from 723 to $923 \mathrm{~K}$ and closed circles indicate samples aged at from 573 to $673 \mathrm{~K}$ had coarse $\beta$ grained structures and which were strengthened using the $\omega$ phase or extremely fine $\alpha$ precipitates. The results clearly show that the strengthductility balance is strongly dependent on the $\beta$ grain size and the kind and morphology of precipitates.

It is also worth noting that the ductility values show a remarkably steep decrease above $1500 \mathrm{MPa}$ in tensile strength as indicated by the broken line in Fig. 2 . It has generally been considered that the relationship between strength and ductility shows a tendency to decrease gradually with increasing strength, as indicated by that of an upper limit of Fig. 2. Accordingly, the fact that ductility shows a drastic decrease above a certain strength level, is connected to the occurrence of the grain boundary failure due to the insufficient grain refinement as mentioned below. ${ }^{8)}$

Figure 3 shows a schematic variation of the strength and ductility as a function of the grain size under constant aging conditions. When the grain size becomes larger than a critical size $A$, the ductility is reduced due to the occurrence of grain boundary failure. Above a critical size B, the ductility becomes zero, which leads to unstable low stress failures and the inability to achieve the full strength corresponding to the aged hardness. It has been reported $^{8)}$ that these critical grain sizes A and B for any alloys become smaller with increases in the strength level. Hence, the grain size should be kept smaller, with higher strength levels, in order to avoid drastic decreases in ductility.

The broken line in Fig. 2 shows that the ductility

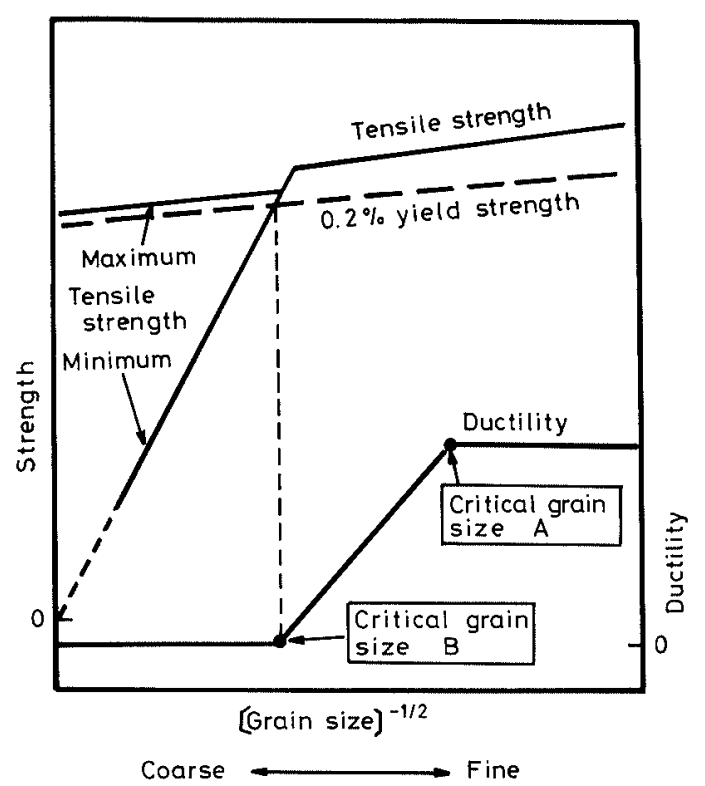

Fig. 3. Schematic variation of strength and ductility as a function of the grain size under constant aging conditions.

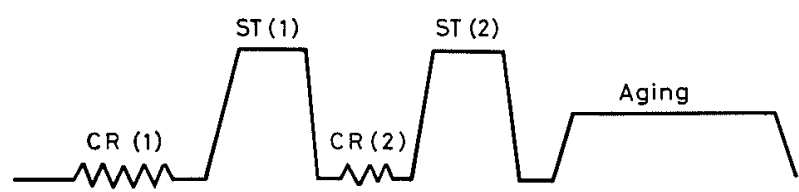

Fig. 4. Schematic representation of a new thermomechanical treatment. 


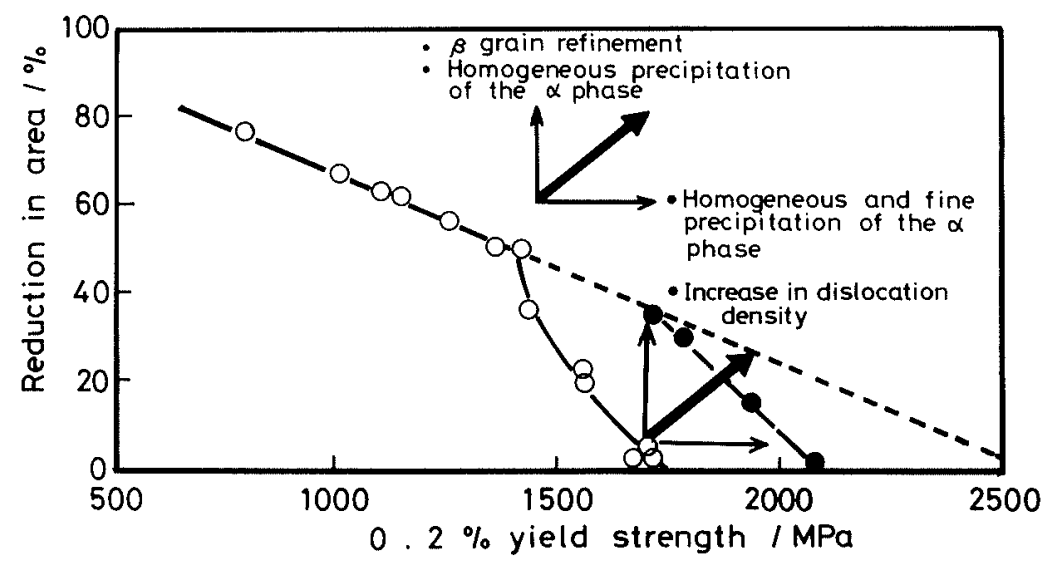

Fig. 5. Schematic representation showing the improvement of the strength-ductility balance by treatments and microstructures.

Open and closed circles indicate upper limit of the balance after heat treatment and the improvement in the balance through applying thermomechanical treatment, respectively.

becomes zero at a strength of about $1700 \mathrm{MPa}$. This means that when heat treatment alone is applied to make the minimum grain size about $50 \mu \mathrm{m}$, unstable low stress failures occur above $1700 \mathrm{MPa}$ and the amount of further strengthening may be limited. ${ }^{9)}$

Therefore, it is necessary to produce additional grain refinement using the thermomechanical treatment for further strengthening. The extrapolated line shown by the dotted line in Fig. 2 may be an attainable upper limit of the strength-ductility balance. This is guidelines for strengthening of titanium alloys.

It has been reported ${ }^{10)}$ that a result of $1900 \mathrm{MPa}$ in tensile strength and $10 \%$ in elongation has been obtained in a Ti-15V-3Cr-3Sn-3Al alloy. This result can be interpreted to mean that the extrapolated relationship in Fig. 2 has been realized experimentally as predicted above. This was achieved by applying the thermomechanical treatment as shown in Fig. 4. The grain size was refined through the first step solution treatment after cold working and the dislocation structure was controlled through the second step solution treatment after cold working. The latter microstructural modification is necessary to obtain the homogeneous and fine precipitation of the $\alpha$ phase and is favorable for producing a moderate recovery structure. Hence, it is very important to select the appropriate amount of cold reduction and solution treatment conditions.

Figure 5 shows schematically the improvement of the strength-ductility balance. An upper limit of the balance after the heat treatment, the improvement of the balance through the application of the thermomechanical treatment, and the effects of microstructures on strength and ductility are indicated in this figure. Ductility is increased by the grain refinement and homogeneous precipitation of the $\alpha$ phase, whereas strength is increased by the homogeneous and fine precipitation of the $\alpha$ phase and by an increase in dislocation density. It is also necessary to refine the dislocation structure for improving both characteristics. The strength-ductility balance can be improved by combining both effects.

\section{Trends of Toughening}

\section{1. $\alpha+\beta$ Alloy}

The mechanical properties of $\alpha+\beta$ alloys are strongly affected by their microstructures. It has been made clear that an equiaxed $\alpha$ structure is effective for improving ductility, whereas an acicular $\alpha$ structure improves fracture toughness. The mechanism of the improvement by the acicular $\alpha$ structure is considered ${ }^{11)}$ to be as follows. Since many microcracks are nucleated at the crack tip before the final unstable fracture, they tend to relax the stress concentration there and to increase the tortuosity of the crack path, which result in the increase in fracture toughness. It has also been reported ${ }^{12)}$ that this improvement is caused by the enhanced extension resistance at the initial stage of crack propagation through an evaluation of $R$-curves. As this improvement is closely related to the easy nucleation of microcracks, it has been called as the "microcrack induced toughening mechanism".

Figure $6^{13)}$ shows the effects of strength level, microstructure, impurity content and testing temperature on fracture toughness (as measured by COD value) in Ti-6Al-4V alloys. Although fracture toughness decreases with increasing strength levels, there is a tendency for it to be improved by the acicular $\alpha$ structure at $273 \mathrm{~K}\left(0^{\circ} \mathrm{C}\right)$ and to be improved at high degrees of purity at $77 \mathrm{~K}$ $\left(-196^{\circ} \mathrm{C}\right)$, irrespective of its microstructure. This purity effect is also reported ${ }^{14,15)}$ as being attributable to the same mechanism as the acicular $\alpha$ structure.

This improvement leads to a decrease in ductility, as suggested by the easy nucleation of microcracks. Ductility and toughness values are both required to evaluate the reliability of alloys. Hence it is very important to increase both characteristics simultaneously by applying various microstructural modification methods.

\section{2. $\beta$ Alloy}

The fracture toughness of $\beta$ alloys is higher than that of $\alpha+\beta$ alloys at given strength levels, as shown in Fig. 7. ${ }^{16)}$ Up till now, the reason for this has not been clearly 
understood. In addition, the microstructure which can improve fracture toughness such as the acicular $\alpha$ structure in $\alpha+\beta$ alloys, has not yet been found. Since $\beta$ alloys are generally solution treated just above the $\beta$ transus temperature, they do not contain any coarse primary $\alpha$ phases and exhibit a microstructure in which the fine secondary $\alpha$ phase precipitates during aging. This is one of the reasons why fracture toughness is higher for $\beta$ alloys than for $\alpha+\beta$ alloys. Figure $\mathbf{8}^{17)}$ shows the $R$-curves for a $\mathrm{Ti}-10 \mathrm{~V}-2 \mathrm{Fe}-3 \mathrm{Al}$ alloy showing the effect of the primary $\alpha$ phase at a same strength. It can be clearly seen that the sample without the primary $\alpha$ phase shows enhanced extension resistance at the initial stage of crack propagation together with the increased crack initiation resistance. It has been suggested ${ }^{18,19)}$
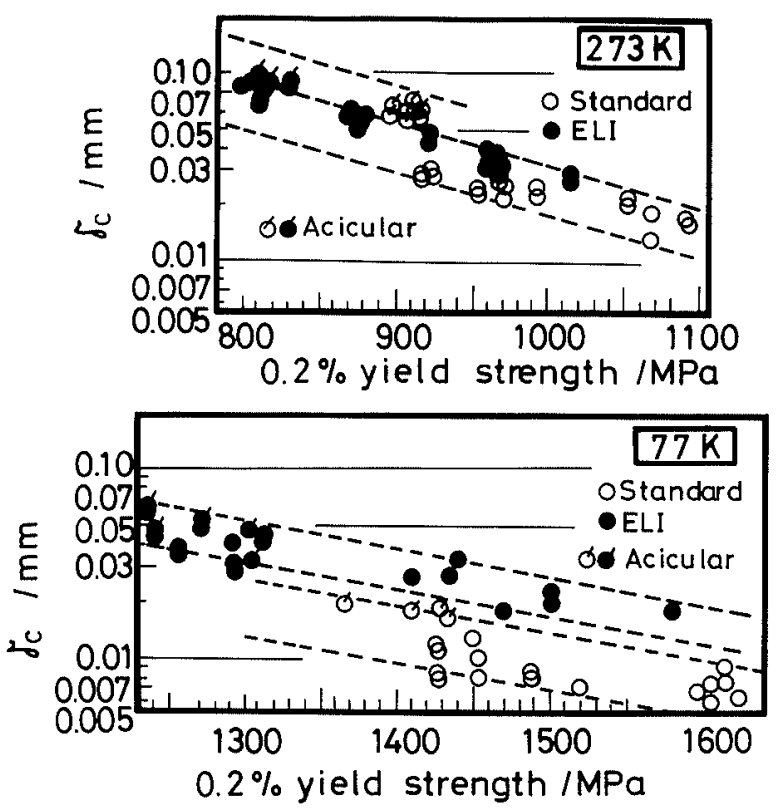

Fig. 6. Effects of strength level, microstructure, impurity content and testing temperature on fracture toughness in $\mathrm{Ti}-6 \mathrm{Al}-4 \mathrm{~V}$ alloys.

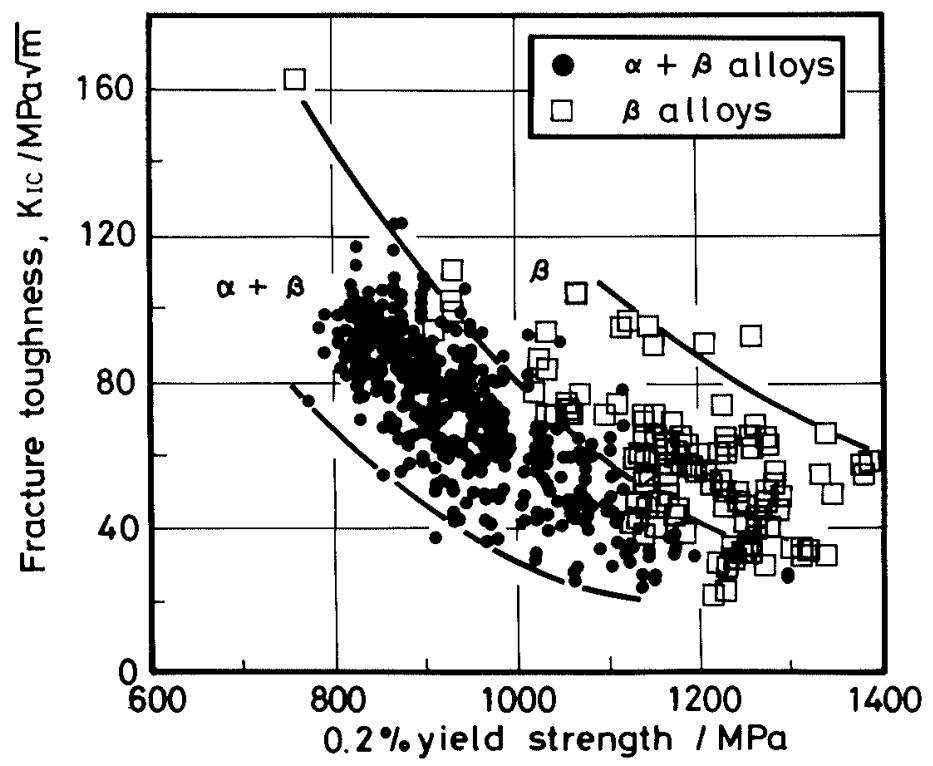

Fig. 7. Relationship between fracture toughness $\left(K_{\mathrm{lc}}\right)$ and yield strength of $\alpha+\beta$ and $\beta$ alloys. that the microcrack induced toughening mechanism is operating in $\beta$ alloys in the same manner as in $\alpha+\beta$ alloys. There are still problems for this hypothesis because the aged $\alpha$ phase precipitates finely and superior fracture toughness is obtained without any compensation in ductility, while the same is obtained with a great decrease in ductility for the acicular $\alpha$ structure in $\alpha+\beta$ alloys.

Figure $9^{7)}$ shows a collection of notched tensile strengths as a function of tensile strength for the various $\beta$ alloys shown in Fig. 2. When toughness is evaluated by notched tensile strength, samples strengthened using the $\omega$ phase or extremely fine $\alpha$ precipitates show a severe embrittlement effect. On the other hand, notched tensile strength does not show the detrimental effects due to coarse grained structures, while the ductility is greatly reduced with the increasing grain size. This is attributed

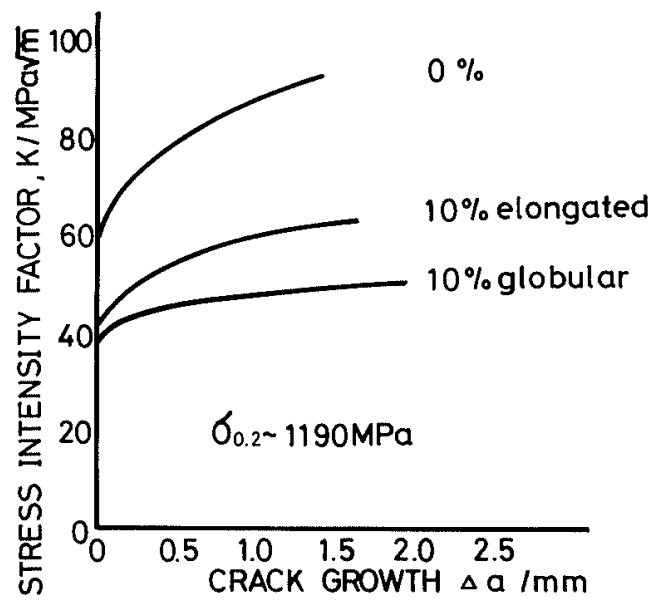

Fig. 8. $R$-curves of a $\mathrm{Ti}-10 \mathrm{~V}-2 \mathrm{Fe}-3 \mathrm{Al}$ alloy showing the effect of different microstructures at the same strength.

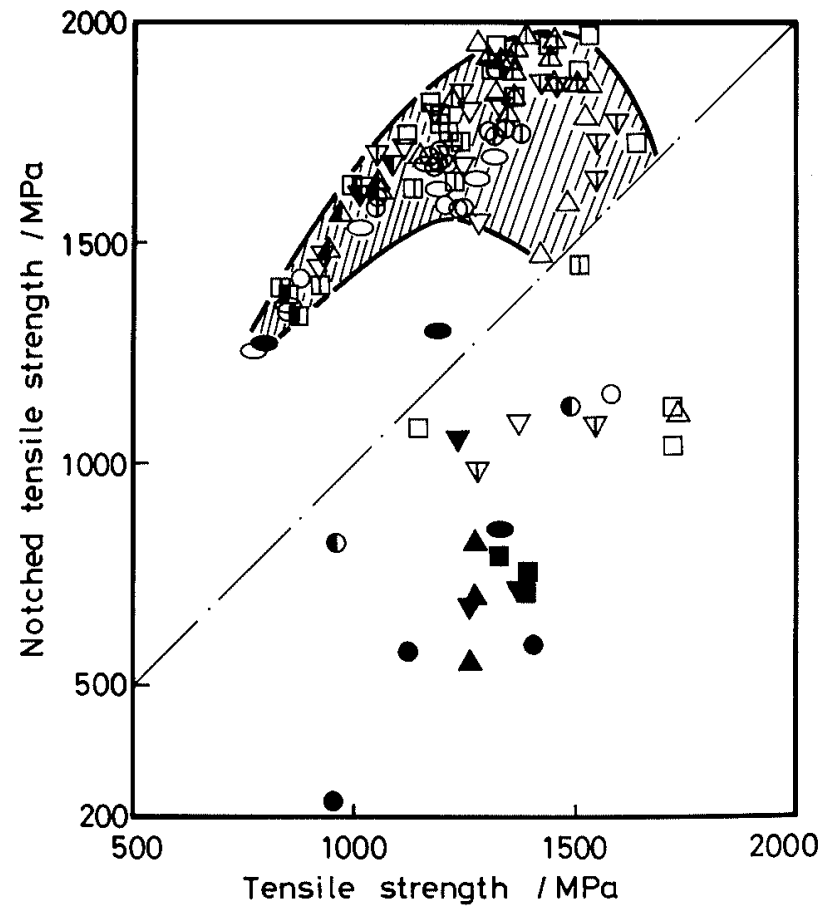

Fig. 9. Relationship between notched tensile strength and tensile strength for various $\beta$ alloys. Stress concentration factor, $k_{\mathrm{t}}$ is 3.5 . 
to the fact that ductility and toughness show different grain size dependencies as explained below.

The notched tensile strength changes from notch strengthening to notch embrittlement conditions with increasing strength levels, as indicated by the hatched region in the figure, when samples are aged above $723 \mathrm{~K}$. The notched tensile strength is reduced to the embrittlement condition with increasing strength levels, even if the microstructures are properly controlled. This is an example of strengthening being limited by toughness. The tensile strength at the point where the ratio between the notched tensile strength and the tensile strength reaches one, is a critical value for strengthening when a notch is present in the specimen. This critical value is about $1700 \mathrm{MPa}$.

Figure 10 shows a collection of $K_{\mathrm{Ic}}$ values as a function of tensile strength for various $\beta$ alloys. $K_{\mathrm{Ic}}$ decreases monotonously with increasing strength level. Samples aged at $773 \mathrm{~K}$, which is the usually used temperature, show that $K_{\mathrm{Ic}}$ is almost independent of the composition and microstructure of th sample and is located within the narrow band shown in the figure. In samples which are strengthened using the $\omega$ phase or extremely fine $\alpha$ precipitates, $K_{\mathrm{Ic}}$ reduces slightly to a level below this

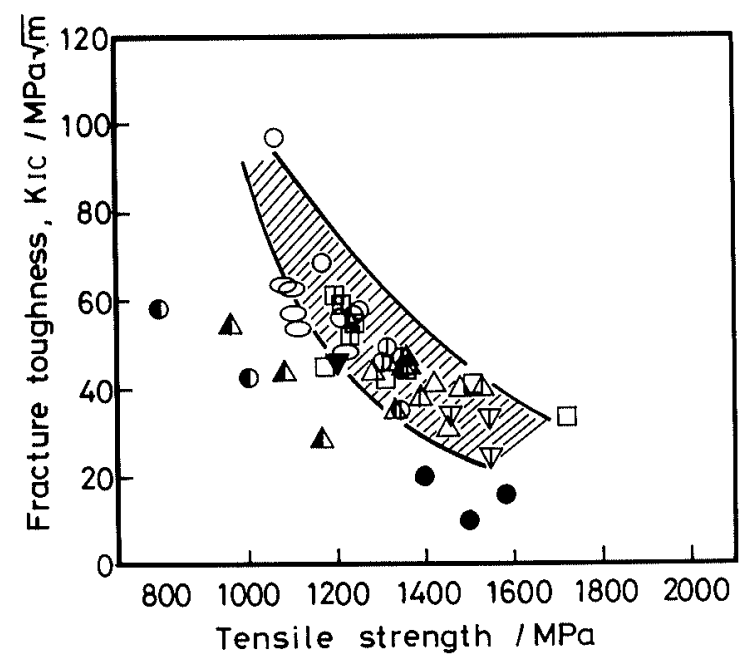

Fig. 10. Relationship between fracture toughness $\left(K_{\mathrm{lc}}\right)$ and tensile strength for various $\beta$ alloys.

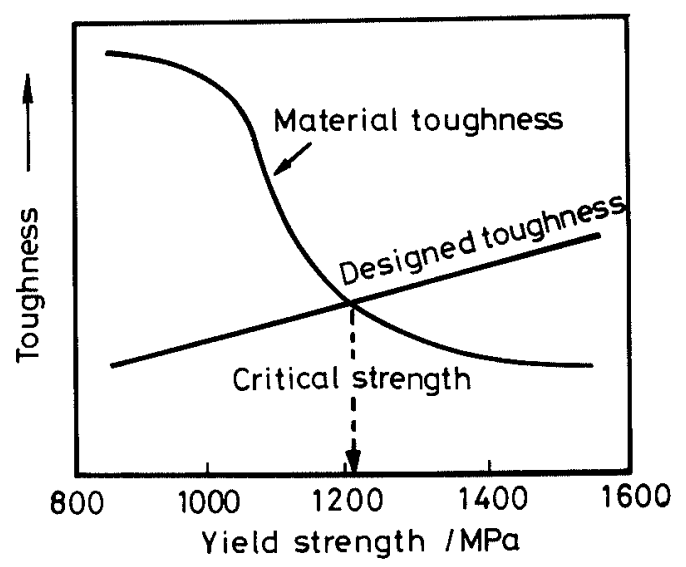

Fig. 11. Schematic representation showing the relationship between material toughness and designed toughness for titanium alloys. band. As mentioned above, $K_{\mathrm{Ic}}$ decreases with an increasing strength level. On the other hand, the designed toughness for assuring the reliability of alloys should be increased with an increase in the strength level, as shown in Fig. 11. ${ }^{9)}$ For the tensile strength to intersect both toughness curves is a critical value for strengthening when a precrack is present in the specimen. This critical value is affected by the size of the precrack and is about $1300 \mathrm{MPa}$ when the diameter of the precrack is assumed to be about $0.3 \mathrm{~mm}$.

\section{Limitations on Strengthening}

As mentioned in the previous sections, increases in the strengths of smooth, notched and precracked specimens are limited by ductility, notched tensile strength and fracture toughness, respectively. As a result, there is a critical value for strengthening for each specimen. Three critical strengths, as measured by tensile strength, are $2000 \mathrm{MPa}$ for smooth, $1700 \mathrm{MPa}$ for notched, and $1300 \mathrm{MPa}$ for precracked specimens, respectively. Thus the possibility for further strengthening will now be considered.

Ductility and toughness are affected differently by grain size. Figure $\mathbf{1 2}^{\mathbf{2 0}}$ ) shows the effect of $\beta$ grain size on ductility values such as elongation and reduction in area and on toughness values such as notched tensile strength and $K_{\mathrm{lc}}$ for a $\mathrm{Ti}-15 \mathrm{~V}-3 \mathrm{Cr}-3 \mathrm{Sn}-3 \mathrm{Al}$ alloy. As is clearly shown in this figure, ductility values can be improved by grain refinement but toughness values cannot. Accordingly, there is a possibility of raising the critical strength when limited by ductility, but it is very difficult to raise it when limited by toughness.

This section has emphasized the limitation for strengthening when the toughness is the limiting factor. However, toughness is not always an indispensable characteristic, depending on the shape and size of structural components and the conditions for applica-

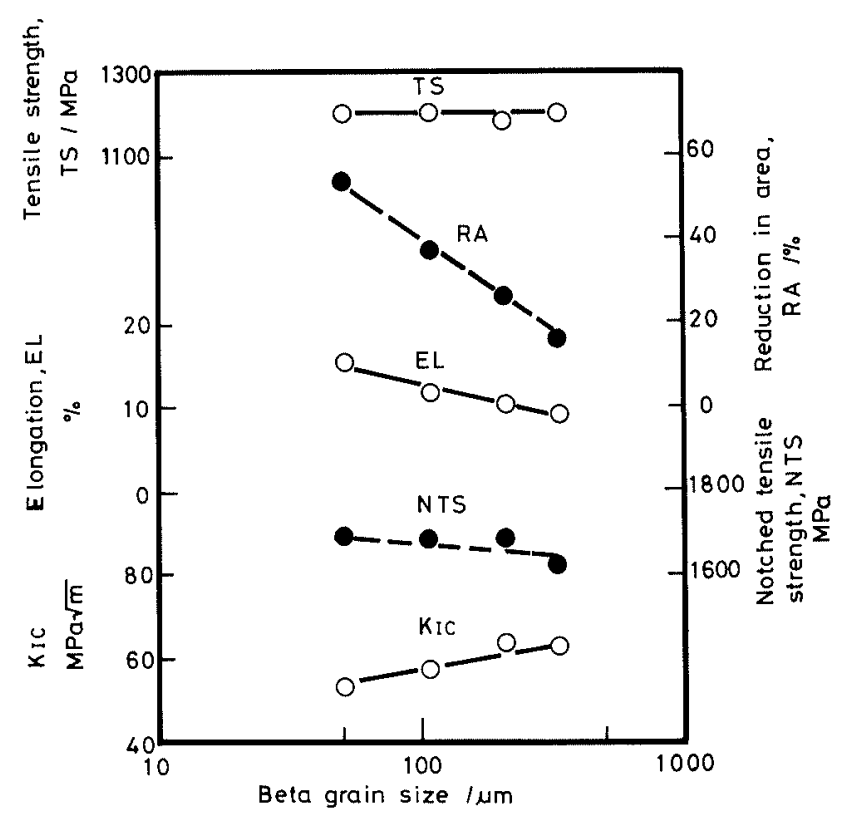

Fig. 12. Effect of $\beta$ grain size on tensile properties, notched tensile strength and fracture toughness for a $\mathrm{Ti}$ $15 \mathrm{~V}-3 \mathrm{Cr}-3 \mathrm{Sn}-3 \mathrm{Al}$ alloy. 
tion. Hence it is very important to increase the strength in the smooth tensile test, but to understand that there are many problems concerning strengthening as mentioned above. This paper explains only the strengthening behavior of alloys without environmental effects. For practical application of high strength alloys, it is essential to evaluate environmental strength and fatigue characteristics.

In conclusion therefore, the strengthening and toughening of titanium alloys should be proceeded with only after due consideration of the above problems.

\section{REFERENCES}

1) Beta Titanium Alloys in the 1980 's, ed. by R. R. Boyer and H. W. Rosenberg, TMS-AIME, New York, (1984).

2) A. Ogawa, K. Takahashi and K. Minagawa: CAMP-ISIJ, 3 (1990), 348.

3) H. Yoshimura, K. Kimura, M. Hayashi, M. Ishii and J. Takamura: J. Jpn. Inst. Met., 54 (1990), 1295.

4) R. A. Wood: Beta Titanium Alloys, MCIC Report-72-11, (1972), 6.

5) F. H. Froes, J. C. Chesnutt, C. G. Rhodes and J. C. Williams: Toughness and Fracture Behavior of Titanium, ASTM STP651, ASTM, OH, (1978), 115.

6) H. Ohyama, J. Miyamoto, Y. Ashida and M. Maki: CAMP-ISIJ, 3 (1990), 344, 1592.
7) Y. Kawabe and S. Muneki: Present Aspects of Titanium Materials Research in Japan, ISIJ, Tokyo, (1989), 147.

8) Y. Kawabe: Tetsu-to-Hagané, 68 (1982), 2595.

9) Y. Kawabe: CAMP-ISIJ, 3 (1990), 1580.

10) C. Ouchi, H. Suenaga and Y. Kohsaka: 6th World Conf. on Titanium, ed. by P. Lacombe, R. Tricot, G. Béranger, Les Editions de Physique, Paris, (1989), 819.

11) T. Kishi, H. Ohyama and K. Kim: Tetsu-to-Hagané, 72 (1986), 123.

12) T. Horiya, H. G. Suzuki and T. Kishi: Tetsu-to-Hagané, 75 (1989), 2250.

13) T. Horiya, H. G. Suzuki and T. Kishi: Tetsu-to-Hagané, 75 (1989), 151.

14) T. Horiya, S. Mashino, T. Kishi and H. G. Suzuki: Proc. 1st Japan Int. SAMPE Symp., Nikkan Kogyo Shinbun, Ltd., Tokyo, (1989), 69.

15) S. Mashino, T. Horiya, H. G. Suzuki and T. Kishi: J. Jpn. Inst. Met., 54 (1990), 153.

16) S. Muneki: Present Aspects of Titanium Materials Research in Japan, ISIJ, Tokyo, (1989), 103.

17) G. Terlinde, H. J. Rathyjen and K. H. Schwabe: Metall. Trans., 19A (1988), 1037.

18) T. Horiya, H. G. Suzuki and T. Kishi: Tetsu-to-Hagané, 76 (1990), 932.

19) N. Niwa: CAMP-ISIJ, 3 (1990), 1612.

20) S. Muneki, Y. Kawabe, T. Kainuma and J. Takahashi: Proc. Ist Int. SAMPE Symp., Nikkan Kogyo Shinbun, Ltd., Tokyo, (1989), 81 